\title{
Pensamento Computacional e Robótica: Um Estudo Sobre Habilidades Desenvolvidas em Oficina de Robótica Educacional
}

\author{
Emiliano José Silva de Oliveira ${ }^{1}$, Ana Liz Souto Oliveira de Araújo ${ }^{12}$ \\ ${ }^{1}$ Departamento de Ciências Exatas - Universidade Federal da Paraíba \\ Rua da Mangueira, s/n, Companhia de Tecidos Rio Tinto 58.297-000 - Rio Tinto - PB \\ ${ }^{2}$ Laboratório de Práticas de Software - Universidade Federal de Campina Grande \\ Av. Aprígio Veloso, s/n, SPLab, Bodocongó 58.429-900 - Campina Grande - PB \\ \{emiliano, analiz\}@dcx.ufpb.br
}

\begin{abstract}
This study investigated how computational thinking can be stimulated by robotic. We identify the essential skills and adapt a robotics' course to boost the computational thinking. As data collection instruments, we used tests, questionnaires and focus groups. The results evidenced that when well planned, robotics can be toward to foster the development of computational thinking skills, especially algorithms, abstraction, decomposition, parallelism and simulation.
\end{abstract}

Resumo. Este trabalho investigou como o pensamento computacional pode ser estimulado nos participantes de oficina de robótica educacional. Identificamos as habilidades do pensamento computacional e adaptamos uma oficina de robótica para explorá-las nas atividades desenvolvidas pelos alunos. Como instrumentos de coleta de dados, utilizamos testes, questionários e grupo focal. Os resultados levantaram indícios que, quando planejada, a robótica educacional pode ser um meio para potencializar o desenvolvimento de habilidades do pensamento computacional, com destaque para as habilidades de construção de algoritmos, abstração, decomposição de problemas, paralelismo e simulação.

\section{Introdução}

A computação possui papel importante na sociedade contemporânea. Todavia, são recentes as iniciativas nas escolas de empregar ferramentas tecnológicas para ensino de conteúdos de computação. A necessidade de estimular o desenvolvimento de atividades ligadas à computação nas instituições de ensino podem ser justificadas pela sua aplicabilidade abrangente em diversas áreas do conhecimento. Colaborando com esse argumento, Sobral et al. (2015, p.5) afirmam que "assim como a matemática é uma ferramenta para modelar adequadamente problemas complexos da física, a computação deveria ser encarada como outra ciência básica, porque está na base de tudo. É preciso pensar na Computação, não como uma ferramenta, mas como uma ciência para a solução de problemas em muitas outras áreas". 
V Congresso Brasileiro de Informática na Educação (CBIE 2016)

Anais do XXVII Simpósio Brasileiro de Informática na Educação (SBIE 2016)

A robótica educacional é defendida como instrumento de mudança no paradigma do ensino em diversos trabalhos, tanto de conteúdos de computação como de outras ciências [Silva, 2009; Fernandes, 2013; e Mattos et al., 2015]. A utilização de conceitos ligados a robótica educacional incita a construção do saber, o que se torna relevante para a aprendizagem dos alunos. Esses conceitos englobam a construção, o aperfeiçoamento e a simulação do seu próprio conhecimento, apoiado pelos conceitos construcionistas [Zilli, 2004].

As revisões de literatura apresentam um panorama do estado da arte sobre o uso da robótica na educação. Quando analisado o objetivo pedagógico das publicações na área, $62 \%$ dos estudos abordam o uso da robótica para o ensino de programação/robótica. Já o ensino de conteúdos escolares específicos através da programação/robótica possuem uma taxa de $17 \%$ de publicação. As outras áreas investigadas, como formação de professores e projetos visando a acessibilidade econômica para o uso de robótica, apresentam taxa de publicação de $12 \%$ e $9 \%$, respectivamente [Lessa et al., 2015].

Diante desse cenário, observamos que são poucas as iniciativas de utilizar a robótica além do ensino de programação ou de conteúdos escolares específicos. Ademais, a robótica pode ser utilizada para estimular outros conteúdos relacionados ao ensino de computação como o pensamento computacional. Pensamento computacional pode ser entendido como uma abordagem de resolução de problemas e compreensão do comportamento humano norteados por conceitos fundamentais da Ciência da Computação [Wing, 2006].

Nesse contexto, este trabalho observa os efeitos do estímulo do pensamento computacional utilizando a robótica educativa como mediadora, uma vez que ambas as abordagens possuem uma intensa relação com conceitos fundamentais da computação. Assim, buscamos responder as seguintes questões de pesquisa: Quais as competências do pensamento computacional que podem ser estimuladas por meio da robótica educacional? Como a robótica educacional pode ser usada para potencializar o desenvolvimento de habilidades do pensamento computacional? Como avaliar o desenvolvimento das habilidades do pensamento computacional estimuladas em uma oficina de robótica educacional?

Para atingir esses objetivos, realizamos uma revisão bibliográfica no intuito de identificar as habilidades do pensamento computacional que podem ser estimuladas por meio da robótica educacional. Em seguida, planejamos uma oficina de robótica para alunos do ensino médio, no intuito de estimular as habilidades identificadas. Utilizamos como instrumentos de coleta de dados pré-teste e pós-teste, além de questionários e um grupo focal. Avaliamos os dados obtidos tanto de forma quantitativa como qualitativa.

Este trabalho segue organizado da seguinte forma: a Seção 2 apresenta competências e habilidades do pensamento computacional; a Seção 3 discute brevemente os benefícios da robótica educacional; a Seção 4 expõe trabalhos relacionados; a Seção 5 descreve os procedimentos e métodos; a Seção 6 apresenta e discute os resultados; e a Seção 7 conclui o trabalho. 
V Congresso Brasileiro de Informática na Educação (CBIE 2016)

Anais do XXVII Simpósio Brasileiro de Informática na Educação (SBIE 2016)

\section{Competências e habilidades relacionadas ao Pensamento Computacional}

Competência é um conjunto de conhecimentos, habilidades e atitudes que justifica êxito em executar uma tarefa [Fleury e Fleury, 2001]. Computer Science Teachers Association $^{l}$ (CSTA) destaca uma lista de competências que são estimuladas no contexto de atividades do pensamento computacional. Essas competências incluem ${ }^{2}$ : confiança em lidar com a complexidade; persistência ao trabalhar com problemas difíceis; tolerância em lidar com ambiguidade; capacidade de lidar com problemas em aberto; capacidade de se comunicar e trabalhar em grupo para atingir um objetivo.

As habilidades relacionadas ao pensamento computacional que permitem desenvolver essas competências são também identificadas pela CSTA. Como forma de facilitar o entendimento, podemos agrupá-las em três partes: o manuseio dos dados, a organização do problema e a resolução do problema, todos eles com suas respectivas habilidades associadas.

Manuseio dos Dados: inclui as habilidades de (i) Coleta de dados que está relacionada à junção das informações e elementos mais significativos para o problema; (ii) Análise dos dados relacionada à maneira como selecionar quais os dados oferecem suporte para a resolução do problema, buscando encontrar padrões e generalizações; e (iii) Representação de dados relacionada a como os resultados obtidos serão apresentados.

Organização do Problema: esta categoria envolve as habilidades de (iv) Abstração relacionada à identificar os aspectos mais relevantes do objeto estudado e assim identificar as caraterísticas essenciais do problema; (v) Decomposição onde procura-se dividir o objeto de estudo em partes menores e mais manejáveis; (vi) Algoritmo é um conceito ligado à ordenação de uma sequência de passos para atingir um objetivo.

Resolução do Problema: inclui as habilidades de (vii) Automação relacionada à utilizar algum dispositivo ou ferramenta para automatizar atividades; (viii) Paralelização relacionada ao ato de sistematizar atividades para que possam ser realizadas em paralelo, poupando tempo e recursos; (ix) Simulação relacionada à forma de representar ou modelar processos.

\section{Robótica educacional}

A robótica educacional possui o benefício de desenvolver diversas competências nos estudantes. Conforme afirma Almeida (2015, p.12), a robótica pedagógica é um meio de instruir os estudantes sobre os conhecimentos da tecnologia atual e "melhorar habilidades e competências tais como o trabalho de pesquisa, a capacidade crítica, o saber contornar as dificuldades na resolução de problemas e o desenvolvimento do raciocínio lógico".

Essas competências são importantes na formação do estudante. Complementando essa visão, Zilli (2004 apud ZILLI, 2002) afirma que as competências

1 CSTA Computational Thinking Task Force. http://www.csta.acm.org/Curriculum/sub/CompThinking.html

2 Operational Definition of Computational Thinking.

http://www.csta.acm.org/Curriculum/sub/CurrFiles/CompThinkingFlyer.pdf 
as quais podem ser desenvolvidas por meio da robótica são: raciocínio lógico; habilidades manuais e estéticas; relações interpessoais e intrapessoais; utilização de conceitos aprendidos em diversas áreas do conhecimento para o desenvolvimento de projetos; investigação e compreensão; representação e comunicação; trabalho com pesquisa; resolução de problemas por meio de erros e acertos; aplicação das teorias formuladas a atividades concretas; utilização da criatividade em diferentes situações.

A motivação em aprender é outro benefício apontado na robótica educacional, pois os alunos se tornam parte ativa da aula. Como muitos alunos desconhecem a robótica, o interesse em aprender sobre aquele objeto torna-se uma chance de dinamizar a aula e adquirir atenção dos aprendizes. Mesmo com a visão lúdica que a robótica pode ser vista, ela exige um grande empenho cognitivo em todas as fases do projeto, desde a construção do protótipo, programação das tarefas, testes, até a versão final do robô.

\section{Trabalhos relacionados}

Almeida (2015) propôs um curso para alunos do $4^{\circ}$ ano do ensino básico usando o kit da Lego Mindstorms NXT. No curso, foram desenvolvidas atividades relacionadas à montagem e programação do robô, atividades de competições e a avaliação do curso por meio de um grupo focal. $\mathrm{O}$ autor concluiu que os conceitos de decomposição de problemas e estruturas de programação, como o uso de sequencias lógicas na resolução das tarefas foram exploradas pelos alunos.

Reis et al. (2015) construíram a Plataforma Coffee. Ela consiste de um robô com um smartphone como processador e um ambiente de programação visual web, baseado em blocos. Eles realizaram um experimento com graduandos de Computação em uma disciplina inicial de programação. Como resultados, os autores constataram que os alunos tiveram um aumento cognitivo relacionados à aprendizagem de programação usando o ambiente de programação visual em blocos.

Trentin et al. (2015) propuseram uma oficina de robótica para professores da educação básica. O objetivo da oficina foi investigar o receio que esse professores possuíam em utilizar os robôs como instrumento pedagógico nas suas aulas. A oficina trabalhou conceitos introdutórios de programação. Como resultado, os autores concluíram que os professores possuíam antes uma visão de aversão ao uso da robótica. Porém constatou que ao fim da oficina mais de $85 \%$ dos professores reconheceram que a robótica é uma ferramenta de ensino, e afirmaram que os kits são de fácil utilização, desde que haja um planejamento prévio.

\section{Procedimentos e métodos}

No presente trabalho realizamos o levantamento bibliográfico no intuito de identificar as habilidades do pensamento computacional que podem ser estimuladas por meio da robótica educacional. Em seguida, adaptamos os planos de curso e de aulas de uma oficina de robótica já existente de forma que as habilidades do pensamento computacional fossem estimuladas de maneira explícita através dos conteúdos de robótica e programação. A oficina anterior tinha como objetivo principal o ensino de programação e foi desenvolvida no contexto do PIBID (Programa Institucional de Bolsas de Iniciação à Docência) de Computação da UFPB - Campus IV. Maiores 
V Congresso Brasileiro de Informática na Educação (CBIE 2016)

Anais do XXVII Simpósio Brasileiro de Informática na Educação (SBIE 2016)

detalhes dessa primeira oficina podem ser obtidas em [Genuíno et al., 2016].

Neste trabalho, os conteúdos de robótica e programação foram planejados para serem desenvolvidos em conjunto com as habilidades selecionadas. A oficina ficou estruturada em 5 aulas, com duração de 3 horas cada, totalizando a carga horária de 15 horas. O Quadro 1 mostra a organização dos conteúdos de robótica e programação juntamente com as principais habilidades estimuladas em cada aula. As aulas 1 e 2 trabalharam a montagem dos kits e as habilidades de coleta, análise e representação de dados, como também abstração, algoritmo e decomposição. As demais aulas trabalharam conceitos de programação, somando as habilidades de paralelização, simulação e decomposição.

Quadro 1: Organização dos conteúdos e habilidades da oficina

\begin{tabular}{|l|l|l|}
\hline Aulas & Conteúdos de robótica e programação & Principais habilidades estimuladas \\
\hline 1 & Montagem do kit Solar Power Oeco Tech & Coleta, análise e representação de dados \\
\hline 2 & Montagem do kit Robo TX Training Lab & Abstração, algoritmo, decomposição \\
\hline 3 & $\begin{array}{l}\text { Linguagem de programação, estruturas de } \\
\text { decisão e de repetição }\end{array}$ & Paralelização \\
\hline 4 & $\begin{array}{l}\text { Sensores e sub-rotinas } \\
5\end{array}$ & Simulação e decomposição \\
\hline
\end{tabular}

Os kits de robótica foram escolhidos entre os existentes na escola pública conveniada ao PIBID. Para seleção, levamos em consideração os critérios de dificuldade de montagem e de suporte para desenvolver o conteúdo e as habilidades planejadas. Os modelos escolhidos foram Oeco Tech e Robo TX Training lab, ambos produzidos pela empresa Fischertechnik®. Estavam disponíveis na escola 5 kits Oeco Tech, onde cada kit possui 180 peças, 1 painel solar e 1 motor. Já do kit Robo TX Training Lab, também estavam disponíveis 5 kits, cada um continha 400 peças, 5 sensores diferentes e 2 motores.

Como instrumentos de coleta de dados para avaliação, elaboramos pré-teste, pós-teste, 5 questionários e realizamos um grupo focal após a última aula. O pré-teste teve o intuito de identificar os conhecimentos prévios dos alunos sobre computação, programação e habilidades relacionadas ao pensamento computacional. Ao final de cada aula, aplicamos um questionário avaliativo com objetivo de mensurar os conteúdos explorados na aula. Na última aula, também aplicamos o pós-teste. O grupo focal buscou identificar na fala dos alunos se eles conseguiam relacionar os conceitos de pensamento computacional com atividades do cotidiano após o término da oficina. Todos os planos de aula e instrumentos de coleta de dados estão disponíveis em [Oliveira, 2016].

\section{Discussão e análise dos resultados}

A oficina foi realizada na primeira quinzena de abril de 2016. Os participantes foram alunos do $1^{\circ}$ ano do ensino médio de uma escola pública da região conveniada ao projeto PIBID de Computação UFPB Campus IV. A seleção dos alunos participantes 
V Congresso Brasileiro de Informática na Educação (CBIE 2016)

Anais do XXVII Simpósio Brasileiro de Informática na Educação (SBIE 2016)

ocorreu de forma aleatória, por conveniência e não foram exigidos requisitos mínimos de conhecimento de informática. Participaram 11 alunos do sexo masculino e 7 do sexo feminino. A média de idade da turma foi de 15 anos. Como houve variação do número de alunos em cada aula, iremos sempre mencionar a quantidade de alunos participantes em cada atividade. Devido a quantidade de kits de robótica disponíveis nas escolas, as atividades foram realizadas em equipes.

\subsection{Pré-teste e pós-teste}

No pré-teste, perguntamos qual a visão do aluno sobre a computação. Dez de um total de dezesseis alunos responderam que a computação tratava-se apenas do manuseio de computador, conforme identificamos nas respostas dos alunos: "É saber mexer no computador e nos programas"; "Usar uma ferramenta para realizar trabalho, estudo e lazer"; "Computador é uma máquina com várias funções, serve para entretenimento, organizar documentos, fazer downloads e jogar games". Outros três alunos definiram a computação como sendo uso da internet. Segundo eles: "Computação é onde a gente pode acessar a rede de internet e pode pesquisar tudo que quiser"; "É interagir com as pessoas e navegar na internet". Dois alunos viram a computação como tecnologia: " $E$ usar a tecnologia para facilitar minha vida"; "É o conhecimento tecnológico por meio da informação". Apenas um respondeu fora desse contexto, pois disse: "Nunca me dediquei muito a computação". Através desses dados, temos indícios de que os alunos possuem uma visão limitada sobre o verdadeiro significado da computação. Observamos que $75 \%$ dos alunos viam a computação apenas como o manuseio de computador e a navegação na internet.

Colocamos no pré-teste uma questão clássica que trabalha algoritmo e raciocínio lógico. O enunciado da questão solicitava que o aluno apresentasse uma solução para o problema de transportar 3 canibais e 3 jesuítas de uma margem do rio para a outra usando um barco com capacidade para duas pessoas. Porém, se em uma das margens, o número de canibais fosse maior que o de jesuítas, os canibais devorariam os jesuítas e a questão seria anulada. No pós-teste colocamos uma questão similar. O aluno deveria apresentar uma solução para o problema de um homem transportar um lobo, uma ovelha e uma caixa de alfafa para o outro lado de um rio usando um barco com capacidade para o homem e um dos animais/objeto. Porém se o lobo ficar a sós com a ovelha, ele a devora e se a ovelha ficar a sós com a caixa de alfafa, ela devora a alfafa.

No pré-teste, todos os 16 alunos participantes não conseguiram responder o desafio corretamente. Já no pós-teste, 15 alunos de um total de 18 conseguiram desenvolver corretamente a questão. A Figura 1 mostra um exemplo de resposta de um aluno as duas questões. Vemos indícios de melhora não apenas no raciocínio lógico (resposta correta no pós-teste), mas também na organização da solução, no qual apresentou uma sequência de passos ordenados. Além disso, o aluno ainda desenvolveu um rascunho, fazendo uma simulação, para melhor estruturar a solução.

\subsection{Demais habilidades e competências observadas}

O pensamento computacional, como uma prática usada na resolução de problemas, deve prezar pela coleta e organização dos dados para que o processo de resolução seja facilitado. Deste modo, trabalhamos na oficina o agrupamento e análise dos dados, para 
V Congresso Brasileiro de Informática na Educação (CBIE 2016)

Anais do XXVII Simpósio Brasileiro de Informática na Educação (SBIE 2016)

que os alunos percebessem a importância de haver uma estruturação de dados. Antes de trabalhar esses conceitos, observamos que os alunos deixaram as peças dos kits misturadas, dificultando a busca pelas peças corretas, fazendo com que eles demorassem mais na montagem do robô. Quando conversamos sobre organização de dados e a importância de utilizar essa perspectiva no dia a dia, eles mudaram a forma de montar o kit. Eles passaram a se preocupar em separar as peças em grupo semelhantes para resolver o problema do tempo de montagem.

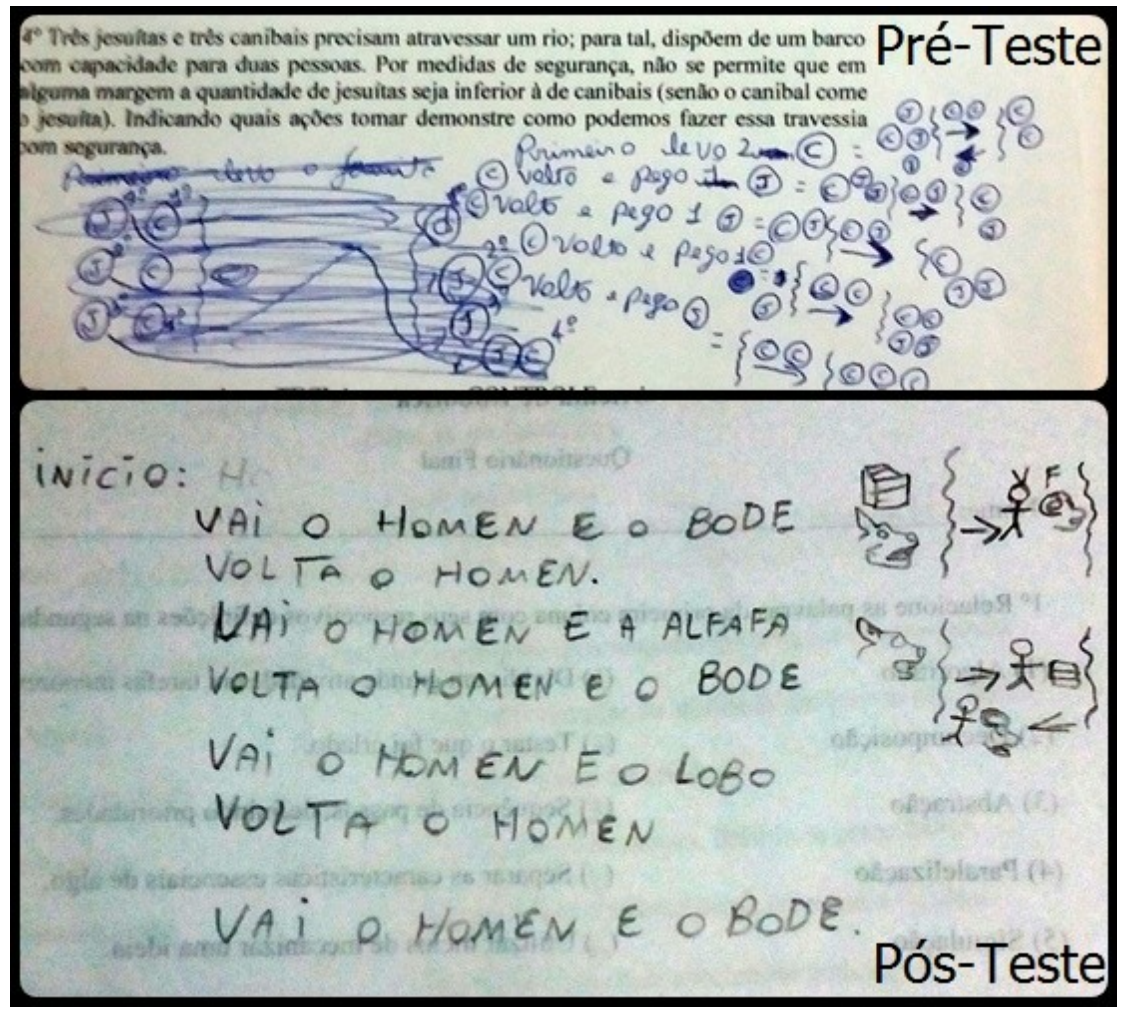

Figura 1. Comparação de resposta de pré-teste e pós-teste.

Abstração foi trabalhada de forma a estimular nos alunos na capacidade de identificar as características essenciais de um objeto ou problema. Quando questionados em uma pergunta objetiva para marcar a opção correta sobre o conceito de abstração, 11 alunos de 17 marcaram a opção "Abstração é identificar as características essenciais". Além disso, há indícios de que eles utilizaram essa habilidade de outras formas, como para descrever melhor o problema (termos essenciais para esclarecer o problema) ou generalizar suas respostas nas atividades propostas na oficina (termos essenciais que devem estar descritas nas respostas).

Trabalhamos a construção de algoritmos ao longo das aulas, tanto na montagem como na linguagem de programação dos kits. Na questão objetiva para marcar qual das opções exemplificava um algoritmo na vida real, 17 alunos de um total de 18 acertaram ao marcarem a opção "Receita de bolo" como resposta correta. Além disso, comparamos a estruturação dos algoritmos produzidos pelos alunos nas perguntas abertas e percebemos melhora na descrição, síntese e organização dos passos.

O conceito de decomposição foi trabalhado de duas formas: (i) como uma 
V Congresso Brasileiro de Informática na Educação (CBIE 2016)

Anais do XXVII Simpósio Brasileiro de Informática na Educação (SBIE 2016)

estratégia de reduzir um problema em pequenas partes e (ii) como a decomposição de código através de sub-rotinas. Os alunos foram questionados de forma objetiva sobre o que é decomposição e 14 de 17 alunos marcaram a opção "Dividir um problema em várias partes, para facilitar sua solução". Uma questão aberta pediu para citar duas vantagens de utilizar sub-rotinas. Onze de 15 alunos acertaram completamente a questão, com respostas como: "Resumir algo grande"; "É um modo mais fácil de executar uma tarefa"; "Deixa o código mais organizado; "Diminuir tempo de escrita".

Quando os alunos foram questionados sobre exemplos de paralelismo durante o curso de robótica, eles responderam: "O robô andar pra frente e ao mesmo tempo piscar as lâmpadas" ou "O robô buzinar e ao mesmo andar". Já em atividades do dia a dia, encontramos respostas como: "Quando eu assisto e como ao mesmo tempo"; "Quando eu escovo os dentes e mexo no celular"; "Quando eu limpo a casa e escuto música no fone". Em ambos os casos, encontramos indícios de paralelismo.

Durante a oficina, ressaltamos a importância do teste prévio e como os alunos poderiam testar através da simulação do fluxo do algoritmo na própria ferramenta de programação. Os alunos realizaram atividades para testar algoritmos e códigos. Destacamos ainda que 8 dos 14 alunos identificaram que poderiam utilizar a sub-rotina para melhorar o processo de teste. Pedimos também para que os alunos escrevessem exemplos de testes que eles executam no seu dia a dia. Obtivemos respostas como: "Quando vou comprar o perfume, tenho que sentir o cheiro primeiro"; "Rascunho de um desenho"; "Verificar se todos os livros que preciso estão na bolsa"; "Botar o celular no wifi e testar se a internet está boa".

No pós-teste, colocamos uma questão objetiva para os alunos relacionarem as habilidades do pensamento computacional trabalhadas com as suas respectivas definições. Consideramos a questão certa apenas aqueles alunos que conseguiram relacionar corretamente todas as alternativas. Doze alunos de 18 responderam corretamente. Notamos que 4 alunos dos 6 que erraram apenas trocaram as definições de decomposição e abstração.

\subsection{Resultado do grupo focal}

O grupo focal buscou identificar se os alunos conseguiam relacionar os conceitos vistos na oficina com as suas atividades do dia a dia. Quando questionados se eles utilizavam algoritmos no seu cotidiano, houve respostas como: "Quando vou a feira com minha mãe e ela faz uma lista do que comprar", "Quando eu defino uma lista de músicas, com as que mais gosto vindo primeiro", "Acho que quando guardo meus livros, deixando os que vou precisar amanhã por primeiro". Esses depoimentos indicam que os estudantes além de compreender o sentido de algoritmo também descobriram que ele está inserido em seus cotidianos.

Exploramos ainda mais a questão de algoritmos, perguntando qual a definição que eles aprenderam de algoritmo. Um aluno respondeu: "É uma sequência de passos, professor". Outro aluno complementou: "Não apenas isso, pois têm que ser passos com preferência". Questionamos o que era preferência. Um terceiro aluno complementou: "É um passo a passo, mas, cada passo tem sua prioridade. Tem que ser realizado em sequência". Assim, levantamos indícios que os alunos conseguem representar 
V Congresso Brasileiro de Informática na Educação (CBIE 2016)

Anais do XXVII Simpósio Brasileiro de Informática na Educação (SBIE 2016)

algoritmos e citar exemplos no seu cotidiano.

\section{Considerações finais}

Este trabalho investigou as habilidades do pensamento computacional que podem ser desenvolvidas nos alunos participantes de oficinas de robótica educacional. Identificamos as habilidades por meio da revisão de literatura e adaptamos uma oficina de robótica para explorá-las. Dessa forma, conseguimos exemplificar que, quando planejado, a robótica educacional pode ser um meio para potencializar o desenvolvimento de habilidades do pensamento computacional. Ao final, avaliamos as habilidades estimuladas por meios de testes, questionários e grupo focal.

Como resultados, levantamos indícios que mostram que os alunos conseguem desenvolver a capacidade de pensar de forma algorítmica para resolver problemas, uma das ideias centrais do pensamento computacional. Vimos também que os alunos, quando estimulados, conseguem relacionar as habilidades e competências trabalhadas na oficina, como algoritmo, abstração, decomposição, testes, simulação e paralelismo nas atividades do cotidiano.

Duas das habilidades inicialmente listadas do pensamento computacional tiveram papel secundário na oficina. As habilidades de representação de dados e automação foram trabalhadas de forma mais discreta, carecendo de mais recursos sobre como explorá-las no contexto prático da robótica. Apesar de parecer contraditório dizer que exploramos pouco a habilidade de automação numa oficina de robótica, ressaltamos que apresentamos diversos exemplos sobre como a robótica pode automatizar atividades repetitivas. Entretanto, devido a escolha dos kits de robótica, não implementamos de fato o robô para substituir uma tarefa repetitiva. A duração da oficina também limitou o tempo disponível para explorar com mais profundidade todas as nove habilidades listadas na literatura.

Como trabalhos futuros, planejamos explorar a habilidade de automação com exemplos do robô substituindo tarefas repetitivas ou tediosas. Em especial, desejamos planejar as próximas oficinas selecionando um conjunto menor de habilidades e explorá-las de forma mais intensa. Em outro trabalho futuro, desejamos comparar os kits de robóticas de diferentes fabricantes no intuito de investigar se pode haver diferença significativa no ensino de robótica e pensamento computacional, baseado nas diferenças entre kits. Assim, poderemos levantar critérios que influenciem a escolha do kit de robótica com o objetivo pedagógico relacionado à computação.

\section{Agradecimentos}

Os autores agradecem à CAPES pela concessão de bolsas do Programa Institucional de Bolsa de Iniciação à Docência - PIBID no período de realização desta pesquisa.

\section{Referências}

ALMEIDA, Carlos Manuel dos Santos. (2015) A importância da aprendizagem da robótica no desenvolvimento do pensamento computacional: um estudo com alunos do $4^{\circ}$ ano. Tese de Doutorado. Disponível em: http://hdl.handle.net/10451/22412. Acesso em: 28 abr. 2016. 
V Congresso Brasileiro de Informática na Educação (CBIE 2016)

Anais do XXVII Simpósio Brasileiro de Informática na Educação (SBIE 2016)

BLIKSTEIN, Paulo. (2008). O pensamento computacional e a reinvenção do computador na educação. Disponível em: <http://goo.gl/YxKxvx>. Acesso em: 2 maio 2016.

FERNANDES, Carla da Costa. (2013) S-educ: Um simulador de ambiente de robótica educacional em plataforma virtual. Disponível em: http://www.natalnet.br/lars/wtdr2012/pdf/106513-W.pdf. Acesso em: 4 maio 2016.

FLEURY, Maria Tereza Leme; FLEURY, Afonso. (2001) Construindo o conceito de competência. Revista de Administração Contemporânea, v. 5, n. SPE, p. 183-196.

GENUINO, R., et al. (2016) Utilizando a robótica para o ensino e aprendizagem de conceitos de programação: um relato de experiência. In: Anais do I Congresso Regional sobre Tecnologias na Educação - Ctrl+E. Natal.

LESSA, V., FORIGO, F., TEIXEIRA, A., \& LICKS, G. P. (2015). Programação de Computadores e Robótica Educativa na Escola: tendências evidenciadas nas produções do Workshop de Informática na Escola. In: Anais do XXI Workshop de Informática na Escola. p. 92.

MATTOS, Sandro Darcy Gaubert et al. (2015) Introdução à Robótica e Estímulo à Lógica de Programação no Ensino Básico Utilizando o Kit Educativo LEGO® Mindstorms. In: Anais dos Workshops do Congresso Brasileiro de Informática na Educação. p. 1418.

OLIVEIRA, Emiliano José Silva. (2016) Pensamento Computacional e Robótica: um estudo sobre habilidades desenvolvidas em oficinas de robótica educacional. 2016. 82f. Monografia (Licenciatura em Ciência da Computação), UFPB, Rio Tinto.

REIS, Cibele Alves da Silva; SARMENTO, Henrique Reinaldo; ZARAMELLA, Vinicius. (2015) Ferramenta de auxílio ao desenvolvimento do pensamento computacional: uma plataforma robótica controlada por smartphone. Disponível em: http://repositorio.roca.utfpr.edu.br/jspui/handle/1/2972. Acesso em: 10 maio 2016.

SOBRAL, Joao Bosco M.; KITTEL, Rosangela; HOPPEN, Angela; MIOTO, Ana Elisa; CRUZ, Fernando A. S.. (2015) Computação no Ensino Fundamental na Escola Pública. Relatório técnico. Disponível em: https://goo.gl/PkMlUR. Acesso em: 9 jun 2016.

SILVA, Alzira Ferreira da. (2009). RoboEduc: Uma metodologia de aprendizado com Robótica Educacional. Disponível em: http://repositorio.ufrn.br/handle/123456789/15128. Acesso em: 15 maio 2016.

TRENTIN, MARCO A. S.; SIGNOR, L.; TEIXEIRA, Adriano Canabarro. (2015) Percepções de professores do ensino básico sobre robótica educativa. Revista Tecnologias na Educação, v. 13, p. 1-11.

WING, Jeannette M. (2006). Computational Thinking. Communications of the ACM, v. 49 , n. 3, p. 33-35.

ZILLI, S. (2004). A Robótica Educacional no Ensino Fundamental: Perspectivas e Prática. 2004. 89 f. Dissertação (Mestrado em Engenharia de Produção) - Programa de Pós-Graduação em Engenharia de Produção, UFSC, Florianópolis. 